\title{
Developing Agriculture Land Mapping using Rapid Application Development (RAD): A Case Study from Indonesia
}

\author{
Antonius Rachmat Chrismanto ${ }^{1}$, Rosa Delima ${ }^{4}$ \\ Program Studi Informatika \\ Universitas Kristen Duta Wacana \\ Yogyakarta, Indonesia
}

\author{
Halim Budi Santoso ${ }^{2}$, Argo Wibowo ${ }^{3}$ \\ Reinald Ariel Kristiawan ${ }^{5}$ \\ Program Studi Sistem Informasi, Universitas Kristen Duta \\ Wacana, Yogyakarta, Indonesia
}

\begin{abstract}
The use of Information and Communication Technology (ICT) in agriculture has become one of the steps to improve agricultural efficiency, effectiveness, productivity, and also expected to encourage the creation of Precision Agriculture. Precision agriculture has an impact on the efficiency of operational costs to increase margins in the production of agricultural products using ICTs. One of the problems that often arise in agriculture is related to the management of agricultural land in each farmer group area. This information is closely related to the needs of agricultural production facilities and infrastructure, such as the need for fertilizers, seeds, and other resources. Web Mapping System is one of the systems to assist in land or area mapping. In this study, the Web Mapping System is expected to be used to help at agricultural land mapping, owned by farmer members of farmer groups. The developed system will store spatial data from farmland members and farmer groups. The Web Mapping System was developed using the Rapid Application Development (RAD) method, where there are several iterative processes. The result of this study is the Web Mapping System for agricultural land. With this application, farmers can find out the status of the land being cultivated or owned. In addition, the Web Mapping System can record the status of the existing land in a farmer group and the need for agricultural production facilities and infrastructure. Further, the Web Mapping System also provides information in a dashboard that can help farmer groups to manage the land owned by each farmer who is a member of the group.
\end{abstract}

Keywords-Farmland; precision agriculture; land mapping system; dashboard; software development

\section{INTRODUCTION}

Agriculture is one of the focused fields of development in Indonesia. Various technologies in agriculture are developed to improve agricultural efficiency, effectiveness, and productivity. Information and communication technology (ICT) is used in the development of information systems for agriculture. Agricultural Information System (AIS) covers a variety of related systems, ranging from land preparation, systems for farmers' data collection, agricultural activities, systems for land management, agricultural activities, crop sales and purchase systems, learning systems for farmers and farmer groups. The development of AIS has done quite a lot in various regions in Indonesia, but most of the existing systems are local and not integrated.
The development of information systems in agriculture has been carried out by a development team from the Information Technology Faculty (FTI) of Duta Wacana Christian University (UKDW) since 2016. To conduct research related to the development and application of Information Technology in agriculture, a study is first carried out to see the readiness of the Indonesian agricultural community in the use of Information Technology [1] and several applications in agriculture that have been carried out [2]. After that, an integrated SIP blueprint was developed by developing Architecture Vision [3], Business Architecture [4], and defining integrated AIS stakeholders [5]. Besides, there are several systems developed, such as the Agricultural Portal [6], Farmer and Farmer Groups Information System [7], Farmers Activity Information System [8], and Information System of Agricultural Products' Purchases and Sales [9]. Three of the four systems developed are ready to be applied in the community. Three systems that have been developed can be accessed via the website at http://dutatani.id [6].

Along with the application of the three existing systems, the next stage of the research to be carried out is to develop a system for mapping of agricultural land and agricultural activities carried out by farmers. The development of this system was carried out because there were problems faced by farmer groups in processing land ownership data, seed requirements, and the estimated amount of agricultural productivity. The manual data processing makes it difficult for farmer groups to produce information related to land area, identification of needs, and level of agricultural production in their area. Indeed, information is needed for a variety of needs including agricultural quality assurance, preparing the needs of seeds, fertilizer, and other resources supporting the agricultural process.

To help farmer groups in overcoming the problem, a system for land mapping and data collection on agricultural activities was developed. This system is developed by Rapid Application Development (RAD) method and is intended to produce spatial information related to land use and agricultural activities that are being carried out. The system is able to integrate various data and display information in spatial form. Therefore it facilitates the analysis process and helps agricultural stakeholders to understand the data. The use of $\mathrm{RAD}$ is based on the suitability of sequential and iterative or 
incremental model characteristics in the process of developing software prototypes. This method is also used in many studies, as in [10].

This paper specifically discusses the process of developing agricultural land mapping systems and dashboards as a user interface between agricultural stakeholders and the system. The paper consists of five parts, preceded by an introduction, followed by a literature review in section II. The application of the RAD method can be seen in Section III, followed by the results and discussion in section IV, and the paper is closed with the conclusion and future work in section $\mathrm{V}$.

\section{LITERATURE REVIEW}

\section{A. Precision Farming}

Precision agriculture is one of the capabilities to handle various activities related to productivity on agricultural land and increase financial benefits, reduce residual production, and minimize impacts on the environment by using data collection, and utilizing the information for strategic decisions on agricultural management using information and communication technology [10]. The use of Information and Communication Technology (ICT) in precision agriculture supports the determination, analysis, and arrangement of changes in agriculture for optimal benefits, sustainability, and preservation for agriculture [11].

Precision agriculture has a good impact on the agriculture sector. Approaches using precision agriculture help to reduce costs and maximize yields [12]. Cost reduction and increased yields encourage increased profits for farmers. The application of precision agriculture also encourages agricultural operational efficiency, particularly for the use of fertilizers and pesticides [13]. This encourages the creation of environmental sustainability and reduces the adverse effects of the use of pesticides and fertilizers. The benefits above are also one of the driving forces that make actors, especially farmers, to implement precision agriculture [11].

\section{B. Web Mapping System for Indonesian Land Mapping}

One application of Information Technology for the agricultural sector is a system for mapping agricultural land. With the land mapping system, spatial data generated is needed for farmers to support the creation of precision agriculture [14]. This system is one step that can be used to map existing agricultural land. The mapping of agricultural land to support precision agriculture was started in 2002 to map fertilizer needs in each of the existing regions [15]. Using this system, fertilizer needs in each agricultural location can be identified more easily. This is certainly considered to support efficiency in managing fertilizer needs [15].

With the development of a mapping system website for agricultural land, there will be operational cost efficiency and also the effectiveness of costs incurred [16]. In addition, this land mapping system can also support land management and reduce neglected agricultural land [17]. Geospatial analysis and prediction models can also be produced by land mapping systems that can be used for agricultural land management [14]. By using a Land Mapping System (SPL) that has spatial data, the system can help to give farmers the ability to visualize

This research is funded by The Ministry of Research, Technology and Higher Education. their land and crops. The use of spatial data in agriculture can also help farmers to understand their agricultural land better and provide information that can support decision making [14].

\section{Rapid Application Development (RAD) Methodology}

According to Denis [18], RAD is a collection of methods developed to overcome the weaknesses of traditional development systems, such as the Waterfall model and its variants. Through a RAD process, organizations can reduce development and maintenance costs [19]. The method used in RAD cycles also provides good software quality compared to the traditional development method approach.

RAD was first introduced by James Martin in the 90s. James Martin believes that the RAD model is more flexible and adaptable to changing user demands and needs and ensures the quality of rapid development with minimal costs [20]. In its application, RAD emphasizes a short planning process by focusing on the software development process, which consists of the development, testing, and reciprocity [21]. The stages of developing a RAD - based system can be seen in Fig 1.

\section{Convex Hull}

A convex polygon, where each inner corner is less than or equal to 180 degrees, is a simple polygon whose interior is a convex set. This means that all vertices of the polygon will point outward, away from the interior of the field [22].

A subset $\mathrm{S}$ of a plane is called convex (Fig. 2) if and only if for each pair of points $\mathrm{p}, \mathrm{q} \in \mathrm{S}$ the line portion $\overline{\mathrm{pq}}$ is contained entirely in S. More precisely, as illustrated in Figure. 3. convex hull is the meeting point of all convex sets containing $S$ [23]. Besides, the convex hull can also be applied to 3D fields such as in Fig. 4 which shows the results.

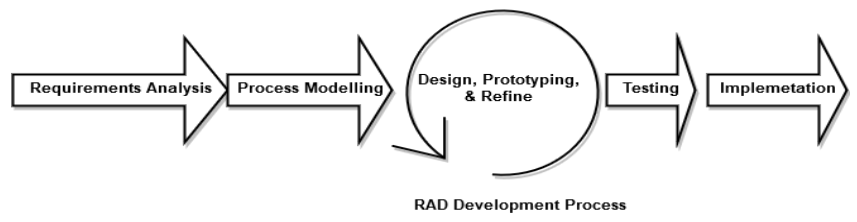

Fig. 1. RAD Development Process.

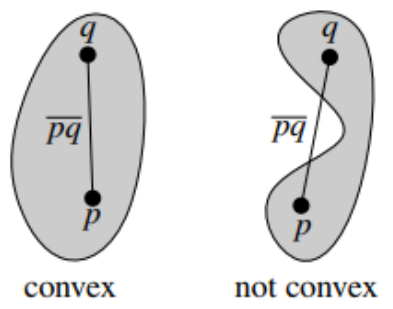

Fig. 2. Convex Example [23].

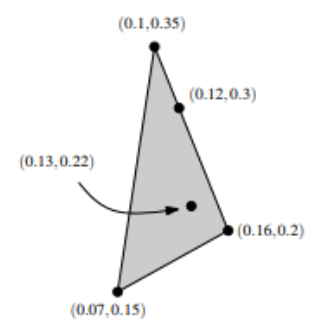

Fig. 3. Convex Hull 2D [23]. 


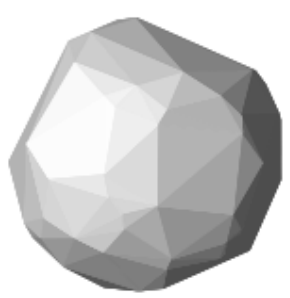

Fig. 4. Convex Hull 3D [23].

Calculating the convex hull is one of the problems in the calculation of geometry. According to Zhongliang Fu, et al. [24] , practically convex hull is widely used in recognizing patterns, image processing, statistics, and GIS. It also used to reconstruct geometric fields. The minimum convex hull of a set of points is a requirement of a GIS application (Fig. 5), such as dynamic area calculation, TIN, and area change.

\section{E. Graham's Scan}

The name Graham's Scan was given in a journal about efficient algorithms for the planar field case, which was published in 1972 by a mathematician named Ronald Lewis Graham. According to a book written by Cormet et al. [25]. The algorithm is a rotational sweep algorithm with good performance characteristics. Because of its speed, Graham's Scan is among the most popular in the search for the convex hull in the planar field.

The algorithm has several variations, but the original version runs in 3 phases:

1) Prepare a set of points as input.

2) Calculates the initial hull.

3) Sweeping to check one by one on the points in order and check whether it is included in the hull.

The first step in preparing a collection of input points is to choose a pivot point for the algorithm. This pivot is usually at the lowest point, then the leftmost in the collection. This point is definitely included in the convex hull [26]. All other points are then sorted by the pivot point as the center. Points that have identical angles are eliminated, the initial starting point from the pivot point is taken, which is the furthest point with the largest angle from the pivot point [25].

The starting hull is simply calculated starting from the pivot point and with 2 starting points that are in a collection of saved and sorted points (P1 and P2). The initial hull was considered as the current hull, which will be updated throughout the algorithm. The sweeping phase considers points in a set of points that have been sorted one by one. For each existing point, it will be determined whether adding this point to the current hull will result in a non-left turn. If the point causes a non-left turn or not, the last point will be removed, and the direction of the turn will be tested again. Turn points are illustrated as in Fig. 6. This continues until you get a left turn, the point will be entered into the current hull. This is repeated until the saved, and sorted points are finished (Fig. 7.) [25]. This figure is modeled Graham's Scan Process [27].

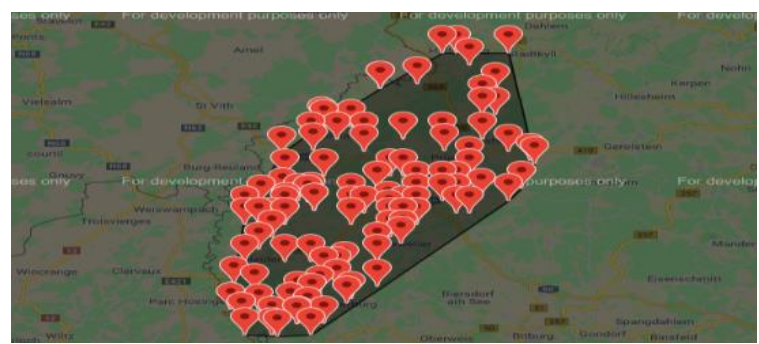

Fig. 5. Convex Hull Usage on Application.

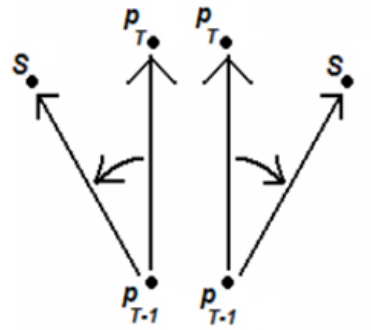

Fig. 6. Left Curve and Right Curve [28].

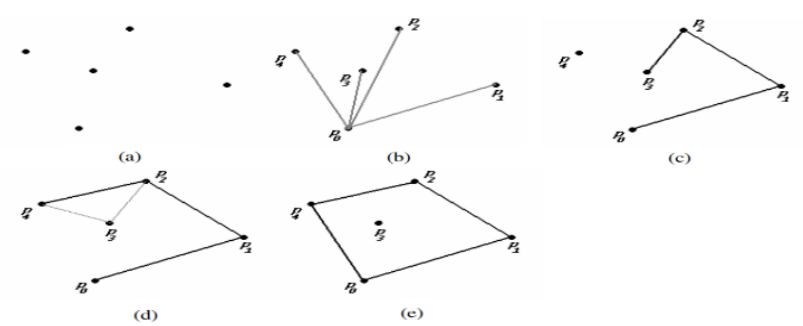

Fig. 7. Graham's Scan Process [27].

\section{F. Google Maps API}

Quoted from Google [28], the Google Map API is a free virtual world map service available online from Google. Google Maps can be opened at the following address https://www.google.com/maps. Google Maps has a feature that can display maps from all over the world, at various scales, and photos of the world from satellites for the whole world in the form of maps. There is also the Google Street View, which provides services to explore the streets with a series of photographs. In addition, it also provides location search and information from a place, travel route, measuring distance from one point to another, view traffic information, save certain places, and place ratings and reviews.

The online API map from Google provides variations to be added to the online map that will be displayed on a web page. As on the example, it can provide variations such as adding markers to a point on the map, which will later be used as a land pointer. The marker can also be added to events, such as if it's clicked, it will bring up the info window as an additional dialog box that points to the marker that was clicked. Then Google Maps also provides variations to make polyline to make lines, polygons to create fields that are formed with many points, other shape fields, and various other variations. The Polygon will be used to describe agricultural land. 


\section{RESEARCH METHOdOLOGY}

The research carried out applies the RAD software development model. The way to apply the RAD model is to combine sequential development techniques and prototyping systems. The dashboard development process is carried out through several stages, such as planning, analysis, design, and manufacture, system testing, and ending with the process of system integration into the dutatani portal. The stages of developing a Web Mapping System can be seen in Fig. 8.

In Fig. 8 it can be seen that in general, the process is divided into 2 stages, such as the sequential development stage, the initial process of planning, data collection, and user requirements analysis. After that, the application development process is continued by means of an iterative and incremental prototyping system. The prototyping system consists of design, coding, and testing activities. A system prototype was produced through this process. As a final activity, an evaluation of the system and integration of the system into the main Dutatani portal is carried out.

\section{A. Planning}

Planning is the initial stage in the system development process. This stage consists of planning the time and resources needed for system development. The system was developed with PHP and MySQL programming languages as the database with 5 people involved in this research.

\section{B. Data Collection}

The data in this study is used in the information system website and recording dashboard, including farmer data, farmer group data, land data, land detail data, species data, land planting data, farmer membership data, land ownership data, and user data and user category data. Most of the data obtained from the database of the main website Dutatani.id system. The data structure obtained from the Dutatani database is as follows: farmer data, farmer group data, farmer membership data, user data, user category data, category type data, plant species data, and regional data. Most of them already have data, but for user data, farmer data, farmer group data, membership data are obtained from Tani Harjo and Tani Rahayu farmer groups. Land data and data structures were obtained from data belonging to Tani Harjo and Tani Rahayu farmers groups.

Land data is also obtained from farmer groups. Using the data obtained, a data structure is created in the database that adjusts the data. Land data, land point data, land planting data, and land photo data are obtained. For land point data and land point detail, it is done by recording using the application directly in the rice fields in Gilangharjo, Pandak, Bantul, Special Region of Yogyakarta, guided by the committee of Tani Harjo farmer group to identify the land and match it with the Google Map online map in the system.

The data that has been obtained is then inputted into the system and then processed by the system to be displayed as a dashboard for calculating land recording and 2 main types of land mapping maps, such as a combined land map and a land distribution map.

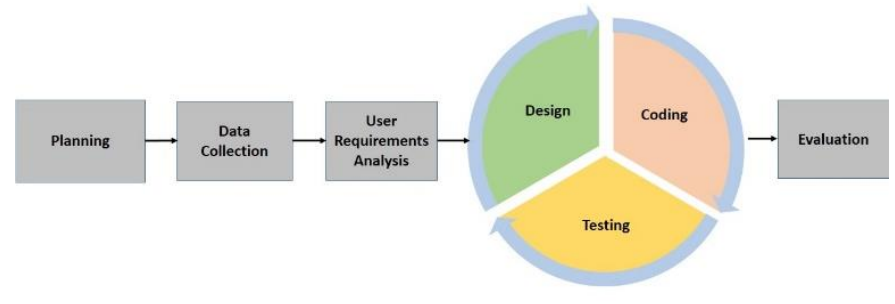

Fig. 8. Research Methodology.

\section{User Requirements Analysis}

The analysis phase is carried out to be able to understand the conditions that apply and identify the system requirements. Before conducting the analysis, the process begins with gathering needs. Techniques used for gathering needs include interviews, questionnaires, and surveys of land mapping systems that have been developed before. Interviews were conducted through small group discussions with system users. Interviews are intended to get the features and services needed by users. Interviews were conducted with farmer group coordinators and farmer group members of Tani Rahayu and Tani Harjo farmer groups. To get the characteristics of users, data collection is done through questionnaires. There were 36 respondents who participated in filling out the questionnaire.

After the data is collected, an analysis is carried out to formulate the functional requirements of the system. The analysis produces a description of the user's characteristics and a list of system requirements. Based on the collected data, the characteristics of the user of the system is obtained as follows.

1) The average age of farmers is 51 years with experience working on rice fields of approximately 25 years. This identifies that the farmer has been trained and has enough experience in managing agricultural land. The work of farmers becomes the main work. Only 15 respondents answered that their job as a farmer is as a side job.

2) Farmers in Gilangharjo manage an average land area of $2000 \mathrm{~m} 2$ per farmer. This land is mostly planted with rice types such as mentik wangi and mentik susu rice. In one year, farmers have 3 growing seasons, where 2 times are planted with rice and 1 time planted with corn, soybeans, beans, and others. This land is mostly privately-owned land with an income of less than 5 million rupiah.

3) Seen from their educational background indicates that almost $50 \%$ of farmers did not graduate from elementary school or only graduated from elementary school. This, of course, will also have an impact on the use and application of technology to assist production and management in this sector. It needs to build the system which is user friendly and easy to use.

\section{Main Design}

The main design for the development of the Web Mapping System is the development of use case diagrams based on the functional requirements of the Web Mapping System, as follows: 
1) The Web Mapping System is capable of recording and managing land data, farmer data, and data of planting in that land.

2) The Web Mapping System has an online map provided through the API service by Google Maps, which will have farmers' land distribution points.

3) The Web Mapping System has info-graphics that display online maps and distribution data.

4) Web Mapping System has filters that can categorize data that will come out on maps and info-graphics.

5) The Web Mapping System can provide statistical calculations from existing land, agriculture, and planting data, which will then be displayed on an infographic dashboard.

The functional needs as the results of the design process are illustrated in the Use Case diagram, as shown in Fig. 9.

Fig. 9 explains the use case diagram of the Web Mapping System for farmland. There are 2 actors, such as the admin who is the representative or administrator of the farmer groups and farmers. The admin is actually a farmer who was appointed to be the committee of a farmer group. As an admin, there are several functional things that can be done, such as accessing land combined maps, accessing land distribution maps, managing land ownership, and accessing the dashboard of the existing system. Whereas farmers have the functions to make land arrangements, look at land lists, manage land point details, record/organize land planting, view land photos, and arrange land photos. To be able to run the features in the system, you need to log in first, either as farmer group's admin or farmer.

\section{E. Detail Design}

The detailed design of the system is done by using several diagrams, such as the Entity Relationship Diagram, Diagram, and Data Flow Diagram. The Entity Relationship Diagram in Fig. 10 explains the relationships between entities in the database used in this study. The schema of the relations in this diagram is used in the recording system and is used in determining simple calculations to be displayed in the Agricultural Land Web Mapping System.

Figure 10 shows the entity relations in the Web Mapping System. There are 17 tables in the ER Diagram. In carrying out land recording, the system will relate to the land ownership recorded in the system. It also relates the land with each detail point, planting, photos. Planting data also has a relation with saprotan (infrastructure for agricultural production) unit data to limit and find out what saprotan (infrastructure for agricultural production) units are available and can be used in recording land planting. In planting, it also records plant species that are related to the information of the plant species that have been stored previously in the main system.

Relationships between farmers and user accounts and categories are also interrelated to indicate the category of the user, whether he is a farmer or an admin who will differentiate his rights in the application. It also takes note of the membership of farmers in farmer groups by looking at the relationship between farmers and their registration in the farmer groups. In addition, there is also a relationship that shows the farmer who functions as a contact person of the farmer group.

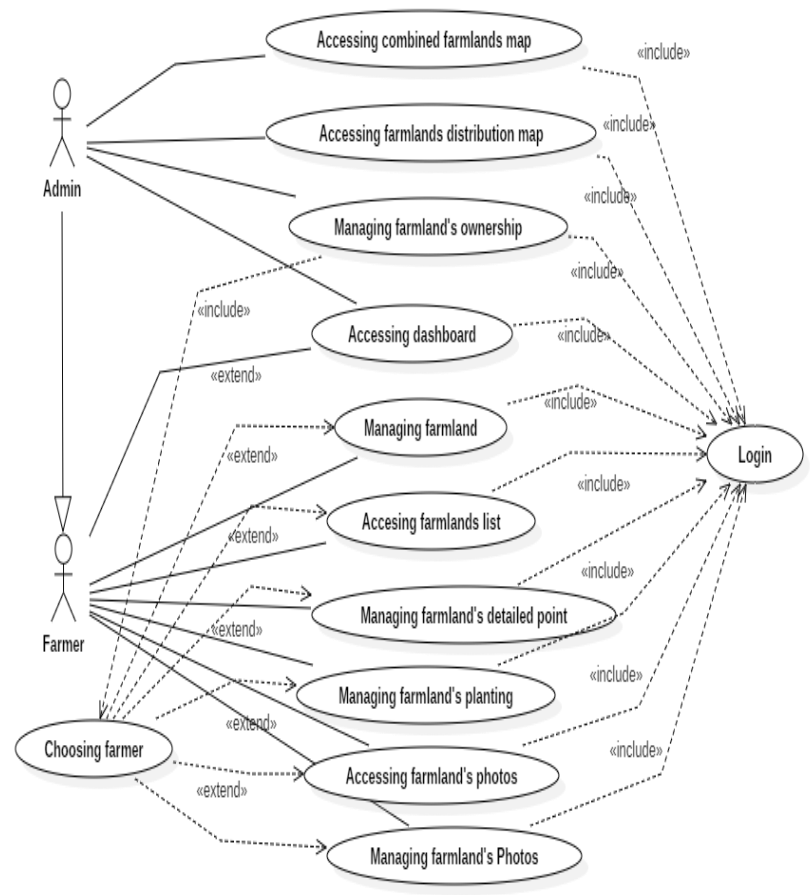

Fig. 9. Use Case Diagram.

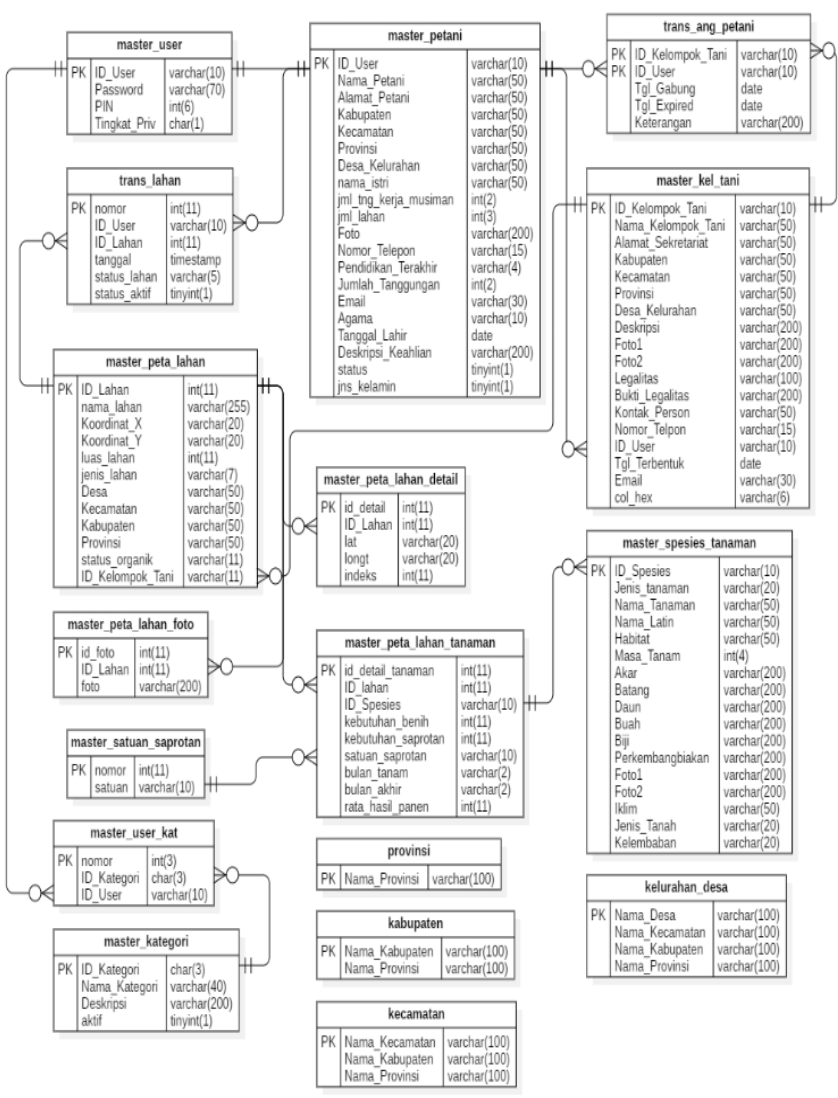

Fig. 10. Entity Relationship Diagram Web Mapping System. 


\section{F. Data Flow and Process Design}

1) Overall process in the system: Fig. 11 explains Data Flow Diagram Level 0 (Context Diagram) from the Web Mapping System. Data flow diagram/DFD is used to describe the data flow in the system. The development of DFD starts from a context diagram to illustrate the system with entities outside the system/stakeholder. There are two outside entities, such as farmers and farmer admin.

Fig. 12 shows Data Flow Diagram Level 1. There are 2 main processes in this diagram, namely the agricultural land data processing and the process of displaying agricultural land information on the dashboard. The Level 0 process is divided into 2 so that the process is clearer. The processes are such as Recording Agricultural Land and Displaying Land Mapping Dashboard. Each of these processes can stand alone, but of course, the dashboard will have results if there has been a previous land recording before. The process of recording farmers' land will be explained in the next section.

2) Recording of farmer's land: Fig. 13 shows Data Flow Diagram Level 2 for the process of land data entry. The process at this level is a more detailed process than the process of recording farmer's land in DFD level 1. This level 2 diagram is illustrated in Fig. 13. All three stakeholders remain at this level. Farmers can carry out the process of adding land directly, while the Admin must make the process of selecting farmers before they can carry out the process of adding land. From the process of adding land, there will be 2 data outputs, such as land data and land ownership data. Then, to go to the process of adding detail to the point of land, adding land planting, and adding photos of land, farmers, and admins who have gone through the process of selecting farmers, must go through the process of selecting land first.

\section{G. Coding and Testing}

System development is done by implementing what already designed in the previous stage of RAD.

\section{H. Evaluation}

An evaluation is carried out to assess the performance of the system. Evaluation is carried out on the time and memory needed by the system as well as measuring the level of use and usability of the system.

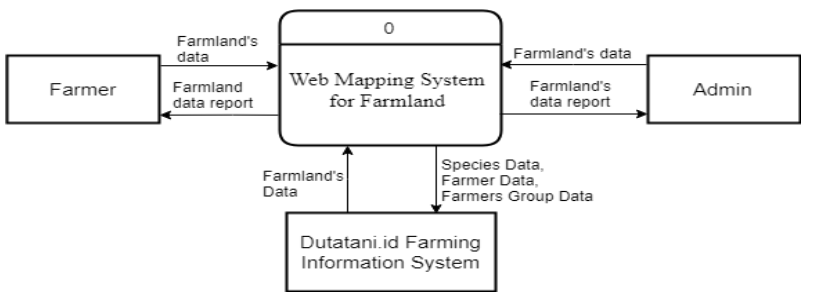

Fig. 11. Context Diagram Data Flow Diagram.

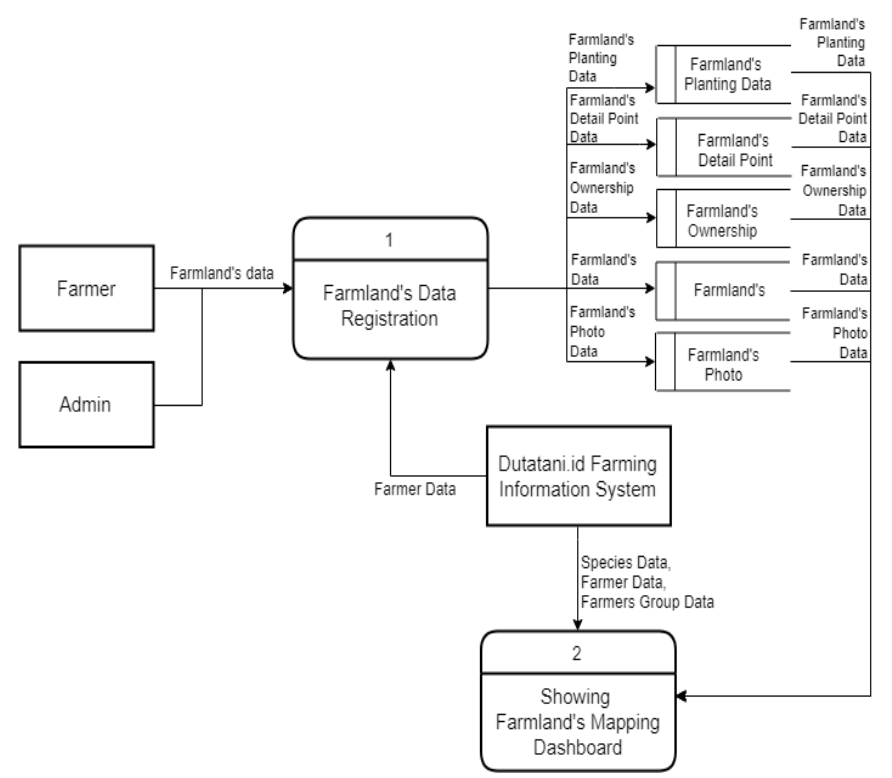

Fig. 12. Data Flow Diagram Level 1.

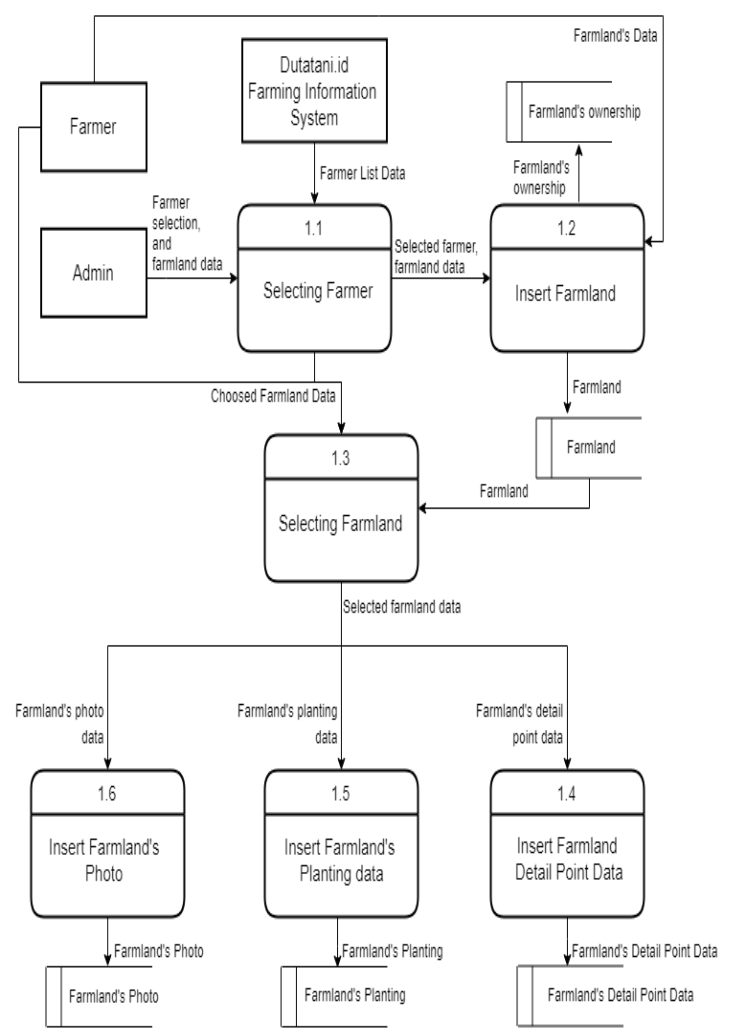

Fig. 13. Data Flow Diagram Level 2 for Land Data Entry.

\section{RESULTS AND DISCUSSION}

At this stage, the results of the application of the system will be explained, which includes an explanation of the process in the land recording information system and a land mapping dashboard, which will later be explained more clearly in each process. This system can be accessed via the URL http://dutatani.id/si_mapping. A description of the land recording information system will include an explanation of how to record the land and record additional data for lands 
such as planting, ownership, and land photos. It is also how the system displays land data. In the mapping, the dashboard will explain how the system displays data. The discussion will include an explanation of the appearance, functions, and processes that occur in the system, accompanied by pictures to help explain the steps that occur in the system being applied.

\section{A. Land Recording Information System}

Land recording information system is part of the system used to register the land and additional information for the land. Additional information for the land is divided into four, such as the details of land points, details of land planting, land ownership, and land photo.

1) Land data recording: The first process in implementing this system is the process of land recording. This land recording process is important because the land data obtained will be used for processing and display in the information system and mapping dashboard on the website. As well as being used as a reference for recording additional land data such as land point details, land planting, land ownership, and land photos.

Fig. 14 shows the farmer data that has been entered into the Web Mapping System. The list of farmers can be accessed by selecting the Farmers Land List menu on the side menu. The page has filters based on the farmer group and the village where the farmer lives, as well as a search bar for farmers' name search. In addition, action options are provided for these farmers, such as adding land and a list of land owned by farmers. The add land button will immediately take the user to the land added form, while the Detail button will take the user to the farm register page of a farmer. In this system, based on the interview result, the land ownership status consists of 3 choices, i.e. owned, rented, and worked on.

2) Land details: The user can view details of the land that has been recorded on the detail page after it has been recorded. The page shows only the basic land data that has been recorded, while additional detail data is still displayed as not recorded. Only land ownership data that has been filled but later it can also be added because the land can be owned or rented or worked on by more than 1 farmer.

3) Land ownership recording: The next recording in the land recording information system is the recording of land ownership. Land ownership data is data that records land ownership transactions and ownership status of a farmer. Ownership status is divided into three, namely Owned, Rented, and Worked On. Ownership status is a status that indicates that the farmer is the owner of the land. TheRented Status is a status that indicates that the farmer is a land tenant, and the worked On Status shows that the farmer is only the worker of the land. This data recording is also important, it is necessary to store ownership transactions which also influence and are used in the process and output of the information system and land mapping dashboard. If this data is not recorded, the land would not appear in the list of land ownership list belongs to 1 farmer, and the land would not be found.
Fig. 15 shows the page for data entry on agricultural land ownership. One land can be recorded in an ownership transaction with more than 1 farmer. Of course, with a different status, because land tenants can be more than 1 per land.

4) Land planting recording: Detailed land planting data is additional data for land that records data on the annual cycle of land about what plants are planted on the land, the seed requirements for the land, the saprotan (infrastructure for agricultural production) requirements on the land, then the saprotan unit, then the planting month and the crop harvest month, and estimated yields from from one time planting with the data. Fig.16 shows the page for location data entry from farmland. Planting data can be added by the user as needed

5) Land photo recording: The next record in the system is the recording of land photographs. This recording records the land photo and saves the photo with the name specified by the system by combining the uploader's user id and the photo file name. Fig. 17 shows pages for images from each recorded land data. To set the land photo, the user can choose the photo detail button at the top of the land photo section. On this page, users can also upload photos and record data in a database. Also shown photos that have been uploaded, and the action to delete photos that can be done for each photo.

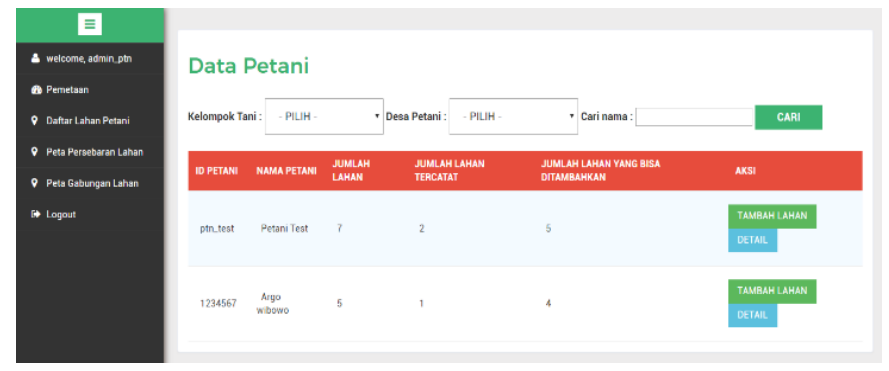

Fig. 14. Farmer Data.

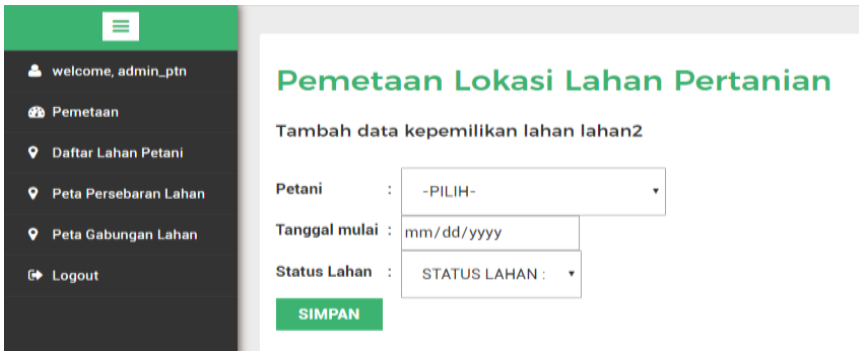

Fig. 15. Farm Land Ownership Data.

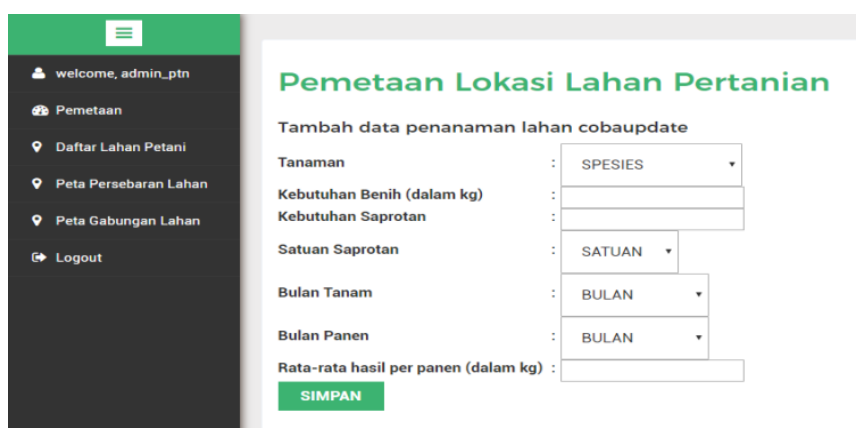

Fig. 16. Form Entry Farm Land Location. 


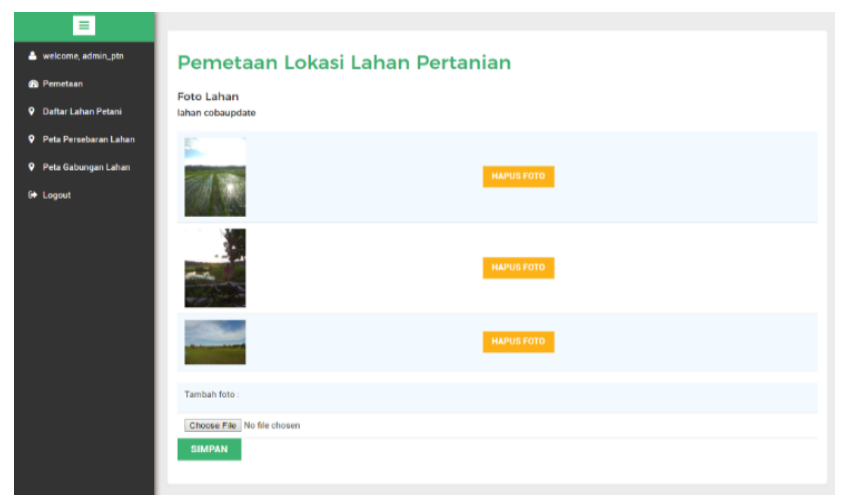

Fig. 17. Farm Land Picture.

6) Land point detail recording: Land point detail data is coordinate data stored to form fields that will be displayed through Google's online maps embedded on this website. The process of recording details of these land points is the second most important after land recording because the details of the points recorded will be used as landforms on the land mapping dashboard that shows the points and land plots on the online map.

Figure 18 shows the Farm Land Polygon. In recording the details of the land points, the user will be asked to select the detail points sequentially and not crossing diagonally between points, because the formation of the polygon fields is arranged sequentially in the order in which the points are recorded. The point detail of the land is used as a guide to form the outer point of the field, which was formed using the Polygon feature provided by Google, as in Fig. 18.

\section{B. Land Mapping Dashboard}

The second part of the system is a simple dashboard for mapping agricultural land which maps land from the existing data and is recorded in the system database and performs land calculations. This land mapping uses 3 types of land distribution maps, namely the Point of Farm Land Distribution Dashboard, which is the main page of this system, then the second is the Land Distribution Map, and finally, the Land Combination Map. Each map has 3 main parts, namely filters, maps, and land calculation information.

1) Map of land distribution point: Point of Farm Land Distribution Dashboard is a map displayed on the main page of the system, which is the distribution of the coordinates of the midpoints of each land, as in Fig. 19. The statistical calculation of land under the map is regulated following the available land data.

2) Map of farm land distribution: Fig. 20 shows a map of the distribution of agricultural land. The second type of map in this mapping dashboard is the Land Distribution Map, which will display all land that has detailed land points and can form fields on the map. Likewise, the calculations performed on this page. This condition is exemplified in Fig. 20.

3) Land combined map: The final type of map is the Land Combined Map. This Land Combined Map is a map that shows the resulting combined fields of land. The map is exemplified in Fig. 21, and Graham's Scan method implemented in the system uses a library to calculate and merge land points.

\section{System Testing}

In this study, a system test was also carried out using a test scenario. There are 16 test scenarios that categorized into three categories as seen in Requirement Traceability Matrix (RTM) in Table I.

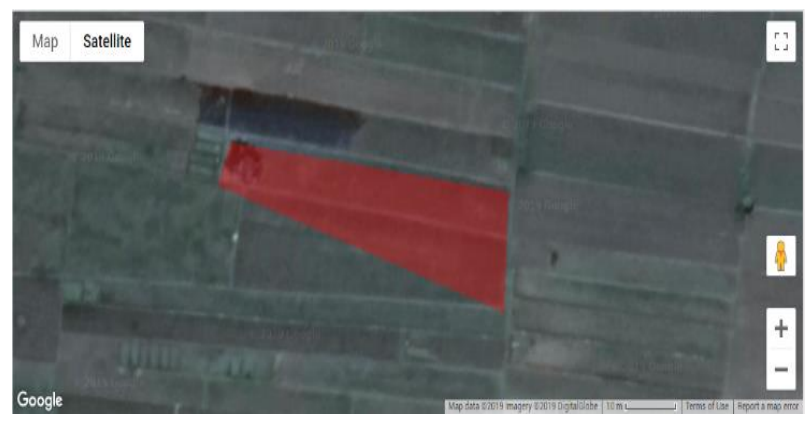

Fig. 18. Farm Land Polygon.

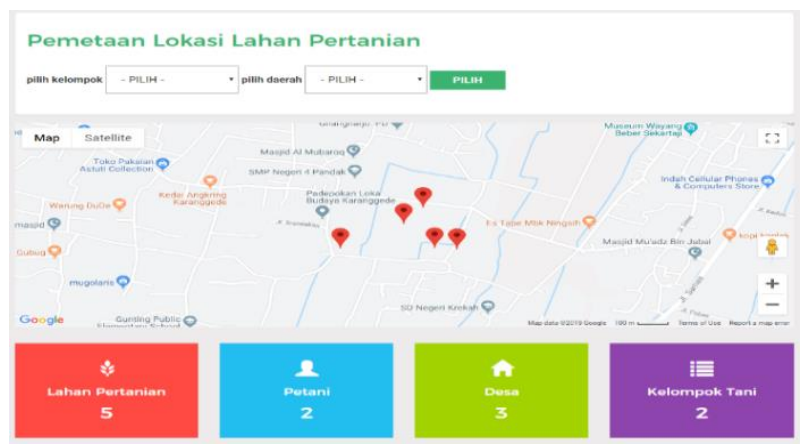

Fig. 19. Point of Farm Land Distribution Dashboard.

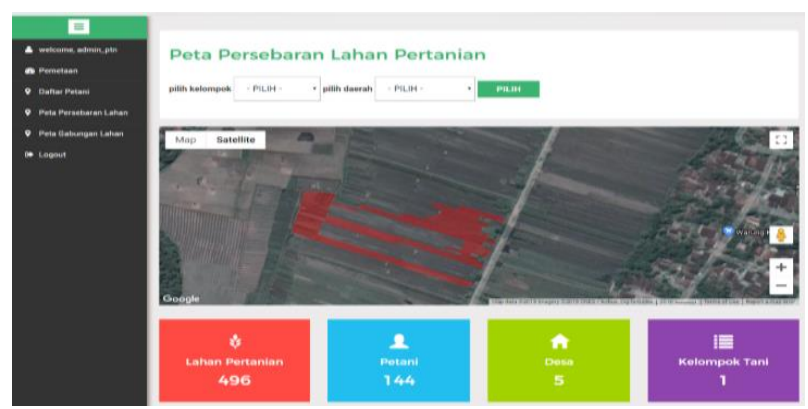

Fig. 20. Farm Land Distribution Map.

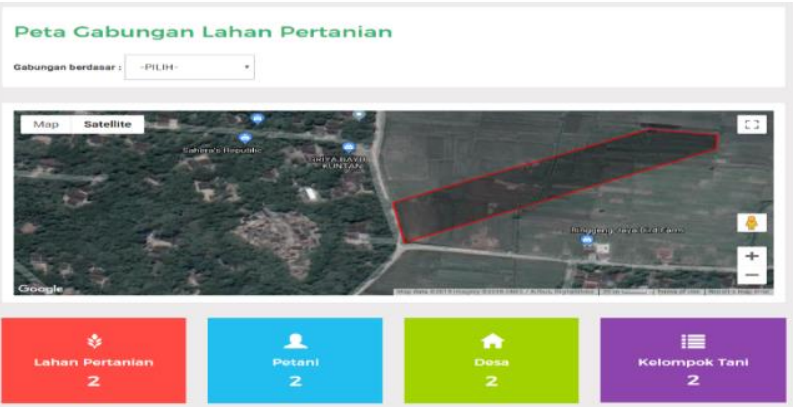

Fig. 21. Land Combined Map 
TABLE. I. REQUIREMENT TRACEABILITYMATRIX

\begin{tabular}{|c|c|c|c|}
\hline $\begin{array}{l}\text { Req } \\
\text { No }\end{array}$ & Req Desc & $\begin{array}{l}\text { Test } \\
\text { Case ID }\end{array}$ & Test Case Scenario \\
\hline 1 & Login & $\begin{array}{l}\text { TA01 } \\
\text { TA02 }\end{array}$ & $\begin{array}{l}\text { Check Url http://dutatani.id/si_mapping } \\
\text { Check Customer Login with invalid Data }\end{array}$ \\
\hline 2 & $\begin{array}{l}\text { Filtering } \\
\text { Maps }\end{array}$ & $\begin{array}{l}\text { TB01, } \\
\text { TB02, } \\
\text { TB03, } \\
\text { TB04 }\end{array}$ & $\begin{array}{l}\text { Check Maps Filtering Features } \\
\text { Change the Maps Mode } \\
\text { Change back the Maps Mode } \\
\text { Check Points Info }\end{array}$ \\
\hline 3 & $\begin{array}{l}\text { Manage } \\
\text { Farmland } \\
\text { Data }\end{array}$ & $\begin{array}{l}\text { TC01, } \\
\text { TC02, } \\
\text { TC03, } \\
\text { TC04, } \\
\text { TC05, } \\
\text { TC06, } \\
\text { TC07, } \\
\text { TC08, } \\
\text { TC09, } \\
\text { TC10 }\end{array}$ & $\begin{array}{l}\text { Check Menu Daftar Lahan Petani } \\
\text { Add the Farmland Data } \\
\text { Update the Farmland Data } \\
\text { Delete the Farmland Data } \\
\text { Add additional ownership data into a farmland } \\
\text { Add additional planting data into a farmland } \\
\text { Add farmland photos } \\
\text { Add Farmland Points } \\
\text { Update Farmland Points } \\
\text { Remove Farmland Points }\end{array}$ \\
\hline
\end{tabular}

From testing to 30 users, it was found that the results were quite good with an average success rate of $74.375 \%$. The results of this test can be seen in Table II and Figure 22.

TABLE. II. TESTING RESULT

\begin{tabular}{|l|l|l|l|}
\hline $\begin{array}{l}\text { Test } \\
\text { Case } \\
\text { ID }\end{array}$ & Test Case Scenario & $\begin{array}{l}\text { Number } \\
\text { Pass }\end{array}$ & $\begin{array}{l}\text { Percentage } \\
\%\end{array}$ \\
\hline TA01 & Check Url http://dutatani.id/si_mapping & 27 & 90 \\
TA02 & Check Customer Login with invalid Data & 22 & 73.33 \\
\hline TB01, & Check Maps Filtering Features & 26 & 86.67 \\
TB02, & Change the Maps Mode & 19 & 63.33 \\
TB03, & Change back the Maps Mode & 24 & 80 \\
TB04 & Check Points Info & 20 & 66.67 \\
\hline TC01, & Check Menu Daftar Lahan Petani & 25 & 83.33 \\
TC02, & Add the Farmland Data & 15 & 50 \\
TC03, & Update the Farmland Data & 22 & 73.33 \\
TC04, & Delete the Farmland Data & 26 & 86.67 \\
TC05, & Add additional ownership data into a & 17 & 56.67 \\
& farmland & & \\
TC06, & Add additional planting data into a & 26 & 86.67 \\
& farmland & & \\
TC07, & Add farmland photos & 28 & 93.33 \\
TC08, & Add Farmland Points & 25 & 83.33 \\
TC09, & Update Farmland Points & 16 & 53.33 \\
TC10 & Remove Farmland Points & 19 & 63.33 \\
\hline
\end{tabular}

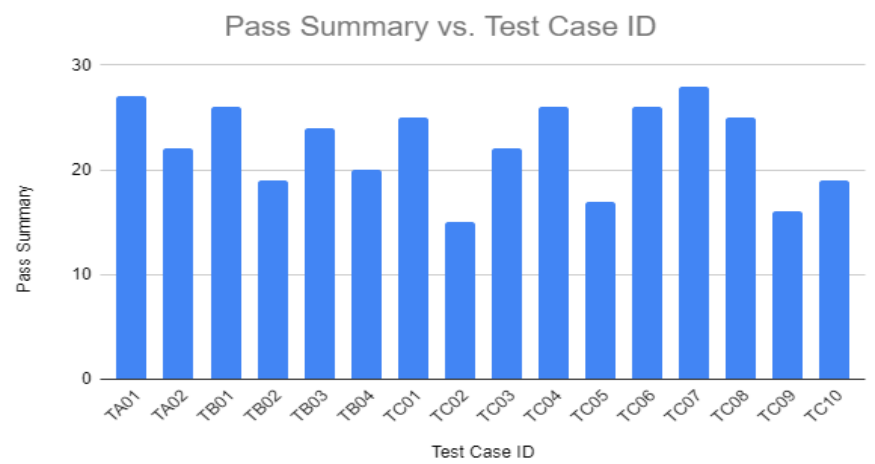

Fig. 22. Statistic of Scenario Testing.
Farm Land Web Mapping System that we developed has some strengths and weaknesses. This system provides information for farmers and management/representatives of farmer groups. This information will help farmers and farmer groups manage land ownership and land processing better. This information is shown on the dashboard that is provided in this system. The limitation of developing this system lies in the mapping of farmland filed formed on the Land Combined Map which covers areas that should not be included in agricultural areas. This is due to the use of Convex Hull Graham's Scan method on the online Google Maps which only detects the outermost point, while the inside will be missed. This can cause data to be biased.

This study gives some practical and academic contributions in terms of developing the Farm Land Web Mapping System. First, this system is built using the real data which got from Tani Harjo and Tani Rahayu Farmer Union. This is a new approach that researchers want to develop by understanding from the farmers what kind of data and information they need. If this system is successful to be built and implemented, researchers want to propose a local government to implement the Web Mapping System in order to help the farmer manage the land well. The developing of Web Mapping System using Rapid Application Development is an iterative and easy way to understand the needs of the user (farmers). Iterative development is needed since farmers do not understand a lot about Information Technology and some of them are digitally illiterate. By using Rapid Application Development, researchers want to understand the business process and farmer information needs Researchers are succeeded to gather the requirement from the farmers and farmer union.

\section{CONCLUSION}

From the results of research on the implementation of the system that has been done, it can be concluded that:

a) Application of Land Recording Information System can create a system for recording agricultural land so that the agricultural land data obtained is structured according to needs and stored in a database so that it can be used easily if needed.

b) The application can display data on a map in the dashboard using data that has been recorded in the database by calling data using the API service and from Google Maps as needed.

c) The application can do the calculation of farmland, farmers, regions and farmer groups to meet the calculation needs that are in the dashboard.

d) The Land Recording Information System application can also create and determine the relationships between farmers and farmland related to the farmers as needed by differentiating land ownership status.

The future works of this research is to measure the level of user acceptance and usability tests of the system. Both evaluations are conducted to get feedback for the final system product before it is implemented to the user. Further development will be built on a mobile-based application to facilitate user access to the system. 


\section{ACKNOWLEDGMENT}

The research team would like to thank the Ministry of Research, Technology, and Higher Education for the funds that have been given to undertake this research with research contract number 227 / SP2H / LT / DRPM / 2019. The research team also thanked the Community Empowerment Research and Empowerment Institute Universitas Kristen Duta Wacana for its support so that this research could proceed well.

\section{REFERENCES}

[1] R. Delima, "Analisis Kondisi dan Kesiapan Masyarakat Tani di Daerah Istimewa Yogyakarta untuk Memanfaatkan TIK di Bidang Pertanian," Yogyakarta, 2016.

[2] R. Delima, H. B. Santoso and J. Purwadi, "Kajian Aplikasi Pertanian Yang Dikembangkan di Beberapa Negara Asia dan Afrika," in Seminar Nasional Aplikasi Teknologi Informasi, Yogyakarta, 2016.

[3] R. Delima, H. B. Santoso and J. Purwadi, "Architecture Vision for Indonesian Integrated Agriculture Information Systems Using TOGAF Framework," in International Conference on Informatics and Computing, Lombok, 2016.

[4] R. Delima, H. B. Santoso and J. Purwadi, "Business Architecture Development for Integrated Agriculture Information System (Iais) Using Togaf Framework," Researchers World, vol. VIII, no. 2(1), pp. 1 - 13, 2017.

[5] H. B. Santoso and R. Delima, "Stakeholder Definition for Indonesian Integrated Agriculture Information System (IAIS)," in The International Conference on Information Technology and Digital Applications, Yogyakarta, 2016.

[6] R. Delima, H. B. Santoso and J. Purwadi, "Development of Dutatani Website Using Rapid Application Development," International Journal of Information Technology and Electrical Engineering, vol. 1, no. 2, pp. 36-44, 2017.

[7] H. B. Santoso, C. Malvin and R. Delima, "Pengembangan Sistem Informasi Pendataan Petani dan Kelompok Tani," in Seminar Nasional Sistem Informasi Indonesia, Sanur, 2017.

[8] R. Delima, F. Galih and A. Wibowo, "Development of Crop and Farmer Activity Information System," Researchers World, vol. VIII, no. 4, pp. 180 - 189, October 2017.

[9] R. Delima, H. B. Santoso, N. Andriyanto and A. Wibowo, "Development of Purchasing Module for Agriculture e-Commerce using Dynamic System Development Model," International Journal of Advanced Computer Science and Applications, vol. 9, no. 10, pp. 86 96, 2018.

[10] S. M. A. El-kader and B. M. M. El-Basioni, "Precision farming solution in Egypt using the wireless," Egyptian Informatics Journal, vol. 14, pp. $221-233,2013$.

[11] S. T. Far and K. Rezaei-Moghaddam, "Impacts of the precision agricultural technologies in Iran: An analysis experts' perception \& their determinants," Information Processing in Agriculture, vol. 5, pp. 173 $184,2018$.
[12] M. Krishnan, C. A. Foster, R. P. Strosser and J. L. Glancey, "Adaptive modeling and control of a manure spreader for precision agriculture," Computers and Electronics in Agriculture, vol. 52, no. 1-2, pp. 1-10, 2006.

[13] D. Breazeale, "A Precision Agriculture Fertilization Program For Alfalfa Hay Production: Will it Pay for Itself," University of Nevada Cooperative Extension, 2006.

[14] M. R. Yousefi and A. M. Razdari, "Application of GIS and GPS in Precision Agriculture (a Review)," International Journal of Advanced Biological and Biomedical Research, vol. 3, no. 1, pp. 7-9, 2015.

[15] Z. Naiqian, W. Maohua and W. Ning, "Precision Agriculture Worldwide Overview," Computers and Electronics in Agriculture, vol. 36, pp. 113 $132,2002$.

[16] G. Pulighe and F. Lupia, "Mapping Spatial Patterns of Urban Agriculture in Rome (Italy) using Google Earth and Web-Mapping Services," Land Use Policy, vol. 59, pp. 49-58, 2016.

[17] H. Yin, A. V. Prishchepov, T. Kuemmerle and B. Bleyhl, "Mapping Agricultural Land Abandonment From Spatial and Temporal Segmentation of Landsat Time Series," Remote Sensing of Environment, vol. 210, pp. 12-24, 2018.

[18] A. Dennis, B. H. Wilom and D. Tegarden, System Analysis and Design : An Object Oriented Approach with UML, United States of America: John Wiley \& Sons, 2014.

[19] R. Naz, M. A. Khan, S. Zulkifar and A. R. Bhutto, "Rapid Application Development Techniques : A Critical Review," International Journal of Software Engineering and Its Application, vol. 9, no. 11, pp. 163-176, 2015.

[20] F. Fatima, M. Javed, F. Amjad and U. G. Khan, "An Approach to Enhance Quality of the Rad Model Using Agents," The International Journal of Science and Technoledge, vol. 2, no. 13, pp. 202 - 210, 2014.

[21] M. L. Despa, "Comparative Study on Software Development Methodologies," Database System Journal, vol. V, no. 3, pp. 37-56, 2014.

[22] Z. P. D. Zhu, Computational Geometry Algorithm Design and Analysis, Beijing: Tsinghua University Press, 2005.

[23] M. D. Berg, O. Cheong, M. V. Krevald and M. Ovemars, Computational Geometry Algorithms and Applications Third Edition, Springer, 2008.

[24] Z. Fu and Y. Lu, "An Efficient Algorithm for The Convex Hull of Planar Scattered Point Set," in International Archives of the Photogrammetry, Remote Sensing, and Spatial Information Sciences, Melbourne, 2012.

[25] T. H. Cormen, C. E. Leirson, R. L. Rivest and C. Stein, Introduction to Algorithms (Third Edition), The MIT Press, 2009.

[26] F. Lanzetta, A. Vaudrey and P. Baucour, "A New Method to Optimize Finite Dimensions Thermodynamic Models: application to an Irreversible Stirling Engine," International Journal of Ambient Energy, vol. DOI: 10.1080/01430750.2017.1310134, 2017.

[27] P. Novandi, "Analisis Kompleksitas Algoritma Pencarian Convex Hull Pada Bidang Planar," Institut Teknologi Bandung, Bandung, 2007.

[28] Google, "How To Use Google Maps," 18 November 2018. [Online]. Available: https://support.google.com/maps/answer/144349?hl=en\& topic $=1687350 \& v i s i t \_i d=636779620492025610-3152190319 \&$ rd=2 . 